\title{
Discussion on Safety Management of Immersed Tunnel in Hong Kong-Zhuhai-Macao Bridge
}

\author{
Yu Wang, Lixin Zhao \\ No. 1 Eng. Co., Ltd. of CCCC First Harbor Engineering Co., Ltd., China \\ Email address: \\ 305080498@qq.com (Yu Wang), 147563102@qq.com (Lixin Zhao)
}

To cite this article:

Yu Wang, Lixin Zhao. Discussion on Safety Management of Immersed Tunnel in Hong Kong-Zhuhai-Macao Bridge. Engineering and Applied Sciences. Vol. 4, No. 1, 2019, pp. 16-20. doi: 10.11648/j.eas.20190401.13

Received: January 13, 2019; Accepted: March 26, 2019; Published: May 9, 2019

\begin{abstract}
In the course of construction of Hong Kong-Zhuhai-Macao Bridge, many works were proceeded simultaneous, such as ballast water tanks and steel seal door removal and transshipment, ballast concrete pouring, site clearance, ventilation, lighting installation and so on. In this paper, we combined with the construction of the immersed tunnel to discuss the safety management, which can be a reference for similar projects.
\end{abstract}

Keywords: Immersed Tube Tunnel, Safety Management, Standardization

\section{Introduction}

The Hong Kong-Zhuhai-Macao bridge immersed tunnel is the first offshore immersed tunnel built in China, the longest highway immersed tunnel and the only deep-buried immersed tunnel in the world. It realizes the conversion between bridge and tunnel, which is the most complicated and difficult part of bridge construction technology, and that is extremely challenging [1]. There are many constructions in the immersed tunnel, and the construction procedure is complicated, so it is difficult to guarantee the safety management. In this paper, safety management experience in immersed tube tunnel is discussed from seven aspects, including safety management, ventilation management, electricity management, fire control management, safety protection, monitoring and communication, and civilized construction, so as to provide reference for similar projects in the future.

\section{Project Overview}

The immersed tunnel of HongKong-Zhuhai-Macao bridge project starts from the Lingdingyang boundary between Guangdong and $\mathrm{HK}$, crosses the tonggu channel and lingding west channel at the mouth of the pearl river, and ends at the west end of the non-navigable bridge at the junction of the West Artificial Island. The tunnel is $5990 \mathrm{~m}$ in length and consists of 33 immersed pipe joints. The standard length of the pipe joint is $180 \mathrm{~m}$ and is prefabricated by the factory method. The immersed pipe prefabrication plant is located in guishan island, about 7 nautical miles away from the construction site. The prefabricated pipe joints are floated to the installation site one by one to be lowered and connected with the buried section of the artificial island or installed pipe joints [2]. After the completion of the connecting, the outer backfill of the pipe shall be carried out immediately, and then the relevant operations in the tunnel are carried out.

\section{Tunnel Personnel Access Security Management}

The construction of the immersed tube tunnel is divided into different working areas. There are numerous constructor and the construction is complex, especially the personnel entering and leaving the tunnel has caused certain difficulties in safety management.

The traditional personnel management mode is to assign a full-time doorkeeper to do personnel registration at the tunnel entrance, or let the passers in and out of the tunnel do the registration by themselves. There are many inconveniences in this way, such as not registering and wrong registering, which are caused by many people coming in and out at the same time. It is unable to record the specific time of entry and exit, let alone make real-time statistics on the personnel in the tunnel. To solve these problems, the project department 
specially introduced "Tunnel Personnel Attendance Safety Management System".

(1) "Tunnel Personnel Attendance Safety Management System" adopts the world's most advanced, open $2.45 \mathrm{~g}$ RFID technology, which can achieve real-time control of the tunnel entry personnel [3]. The implementation of all these can be done just by pasting a coin-sized chip inside the helmet, which pre-record the name, type of work, team and other basic information of construction personnel. Once someone enters the tunnel, the chip attached to the helmet will continuously transmit microwave signals to the system, the LED screen at the entrance of the tunnel will immediately display the information of the person. Specific times of entry and exit of each person can be displayed on the screen .

(2) For outside visitors to enter the tunnel, they need to sign the "tunnel visit approval form" issued by the general manager, hold the "tunnel visit approval form" and make strict registration at the tunnel entrance before entering, and all the people entering the tunnel should wear helmets and reflective vest.

(3) In order to avoid chaos and injuries caused by vehicles and personnel entering and leaving the tunnel at the same time, the entrance and exit of the tunnel are divided into roadway and sidewalk, to avoid the contact between vehicles and pedestrians and ensure the safety of entering and exiting the tunnel.

\section{Ventilation Safety Management}

Different from ordinary tunnel excavation, Hongkong-Zhuhai-Macao bridge tunnel project adopts sunk cement pipe docking method. After each sunk pipe docking, the end steel seal door shall be removed. During the demolition process, harmful gas and smoke are emitted from the carbon arc air gouging operation. If not removed in time, it will affect the health of the construction personnel. And the tunnel is in a semi-closed state, it is not easy for air ventilation, tunnel construction dust and vehicle exhaust emissions will cause air pollution inside the tunnel, which will pose a threat to workers health and safety.

To this end, the project department installed high-power axial flow fans with a diameter of nearly three meters on both sides of the tunnel. Huge ventilation pipes were set up at the top of the tunnel to continuously deliver fresh air to the deep tunnel [4]. A number of large exhaust fans were placed at each construction site to discharge harmful gas and smoke out of the tunnel in time.

In order to prevent the exhaust gas from entering the tunnel again, the project department also adopts the method of "blocking", and sets smoke curtain at the entrance of the tunnel to separate the fan inlet from the exhaust gas outlet, to ensure that the air entering the tunnel is fresh and pollution-free.

In order to ensure the ventilation effect, the project department has set up a ventilation team. The team members must be proficient in ventilation system performance, strictly abiding by the operation rules and only after passing the training and assessment can they actually work. Ventilation team members conduct ventilation safety inspection every day, and immediately repair the bending and breakage of ventilation pipes. Special personnel will be arranged to use air detection instruments and PM 2.5 air quality detectors to monitor air quality in the tunnel every day [5], and the test results will be publicized at the entrance of the tunnel. Once the air quality exceeds the standard, the construction personnel will be informed to take protective measures or evacuate in time, and ventilation of the working areas shall be carried out immediately.

In addition, in order to keep the tunnel workers healthy, the project department has specially equipped the tunnel workers with self-suction dust respirators. In order to strengthen the emergency treatment of emergencies, the project department has installed two air respirators on the site. Once the on-site construction personnel have breathing difficulties, poisoned and other conditions, the air respirator shall be used immediately to supply air, and the construction personnel shall be organized to depart from the dangerous area to ensure their health and safety [6].

\section{Tunnel Electricity Safety Management}

The TN-S system is used for power supply in the tunnel, and three-level control and two-level protection are implemented according to the requirements of the specification [7]. The switch boxes on the construction site are uniformly numbered, and the responsible person shall be clearly identified. The inside and outside of the switchbox shall be kept clean and tidy. The power line in the tunnel shall be inspected and repaired by a specially assigned person. During the inspection and maintenance, the power shall be cut off and the construction work units in the pipe shall be informed in time and the personnel shall be on duty.

In order to strengthen the safety management of the switchbox on the construction site and ensure the safety of the construction electricity, the electricians shall inspect the switch boxes and wires every day [8].

\section{Fire Safety Management}

The tunnel of Hong Kong-Zhuhai-Macao Bridge is completed by immersed pipe docking, and each joint of the immersed pipes is connected with a rubber water stop. Once fire in the tunnel causes damage to the water stop, seawater will leak into the tunnel, posing a threat to the life safety of the construction personnel inside the tunnel, and also immersing the tunnel, which are catastrophic. Therefore, it is necessary to strengthen the fire safety management in the tunnel, strictly control the fire source and combustible materials in the tunnel, and equip with enough firefighting facilities.

\subsection{Control Combustible Materials}

The removal of steel seal doors in the tunnel requires hot work, so the quantity of oxygen, acetylene or propane gas 
cylinders should be strictly controlled in the tunnel. The gas cylinders should be stored in a warehouse on the artificial island. When the cylinders are needed, they should be transported to the temporary storage point of the tunnel and then to the operation area by forklifts.

Inflammable and explosive articles such as gasoline and diesel shall not be stored in the tunnel. The fuel tanks of all types of vehicles must not exceed one third of their own fuel tanks.

\subsection{Fire Fighting Facilities}

There is an effective and sufficient number of fire fighting equipment in the tunnel. A $30 \mathrm{~kg}$ trolley-type fire extinguisher is set at the junction of each sunken cement pipe, 2 dry powder fire extinguishers $(4 \mathrm{~kg})$ are set at the water stop of each section, and 2 carbon dioxide fire extinguishers $(4 \mathrm{~kg})$ are set at each box transformer. All of the facilities above are equipped with obvious signs [9].

\subsection{Fire Source Control}

Whoever enters the tunnel shall not bring matches, lighters or other kinds of fire. If the visitors or inspectors carry such things with them, they shall store these fire sources in the safety deposit box at the tunnel entrance [10]. Anyone who needs to carry out fire operation in the tunnel shall go to the project department to get approval in advance. Fire watchers should be assigned at the scene of hot work, and combustibles near the working surface should be cleaned and fire extinguishers should be equipped [11].

In order to facilitate construction personnel to rest and smoke in the tunnel, the project department specially set up a smoking area in the tunnel, and made an electronic cigarette lighter according to the principle of automobile cigarette lighter. The cigarette lighter uses a battery as a power source, which is small in size, simple in operation, and avoids the fire hazard caused by open flame. The smoking area shall be equipped with fire extinguisher and stainless steel dustbin, and the cigarette ends shall be put into the ashtray uniformly.

\section{Immersed Tunnel Safety Protection Measures}

\subsection{Safety Protection}

In the tunnel, sideways and roadway are set up to shunt people and vehicles shunt (figure 1). Standardized guardrails are used to separate the roadway from the sidewalks, reflective barriers are placed on two side ditches, and roadblocks are set up on one side of the sidewalk and connected by connecting rods. To improve the safety warning condition in the tunnel, warning lights are installed on the safety guardrails to remind passing vehicles and pedestrians to pay attention to safety [12]. Vehicles are uniformly parked in the designated parking space, and anti-slip car blocks are set.
Standard pedals shall be uniformly used for temporary passageways in the tunnel. Cross-pipe corridor passageways shall be equipped according to the number of safe passageways designed. Adjustable height shall be adopted for the step ladder according to the structural characteristics of sunken pipe (figure 2). Safety warning signs are hung at the entrance of the safety passage, and guidance signs are set at the holes of walls [13].

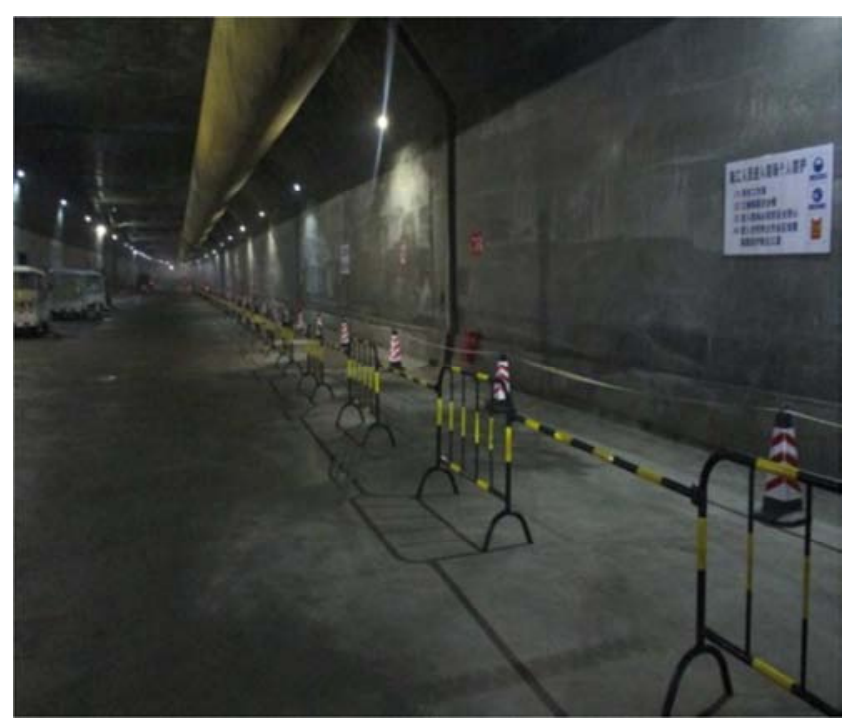

Figure 1. The separation of people and vehicles.

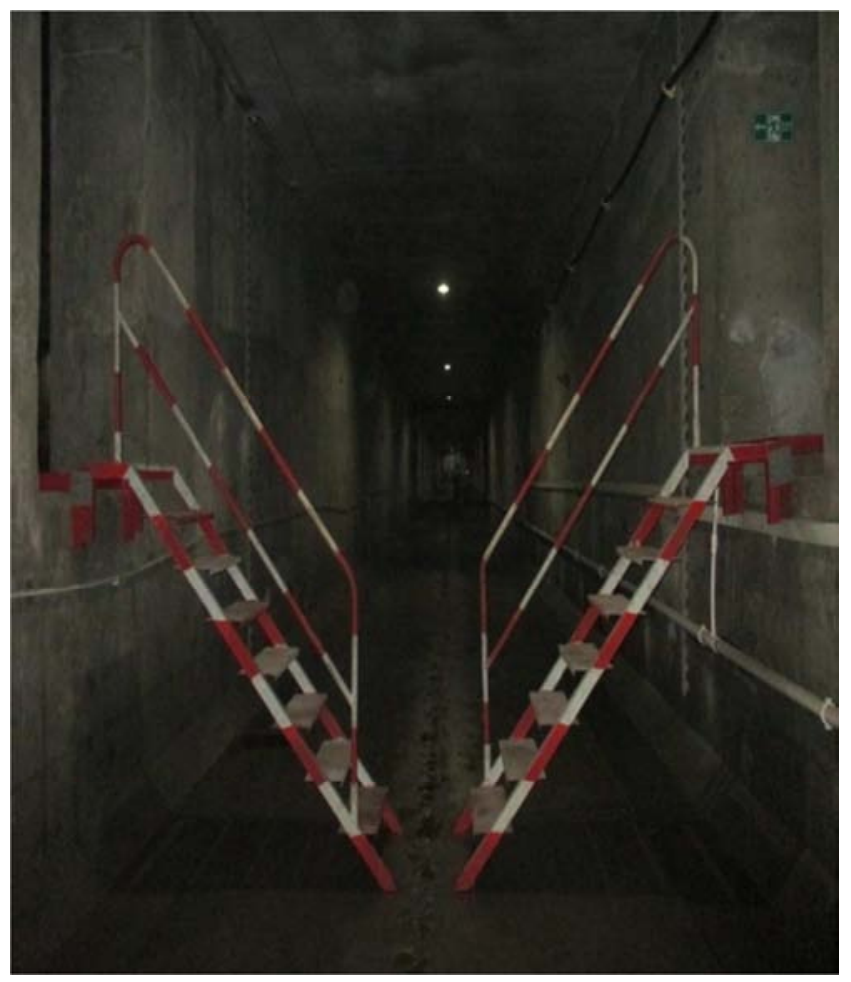

Figure 2. Step ladder standard.

\subsection{Safety Warning Signs}

According to the principle of internationalization and standardization, the safety warning signs in the tunnel are set 
uniformly in accordance with the visual identification system, and referring to the "Standardization Guide for Highway Waterway Engineering Construction" and Japanese site.

Large construction signs (figure 3) shall be posted at the tunnel entrance, including construction brief introduction, instructions for entering the tunnel, fire escape route, HSE management policy, hazard source identification and control method, operation schematic diagram, air quality and weather forecast, etc.. Each pipe joint in the tunnel shall be marked with a sign, safety warning signs shall be posted on both sides of the wall, safe passage ports and dangerous areas.

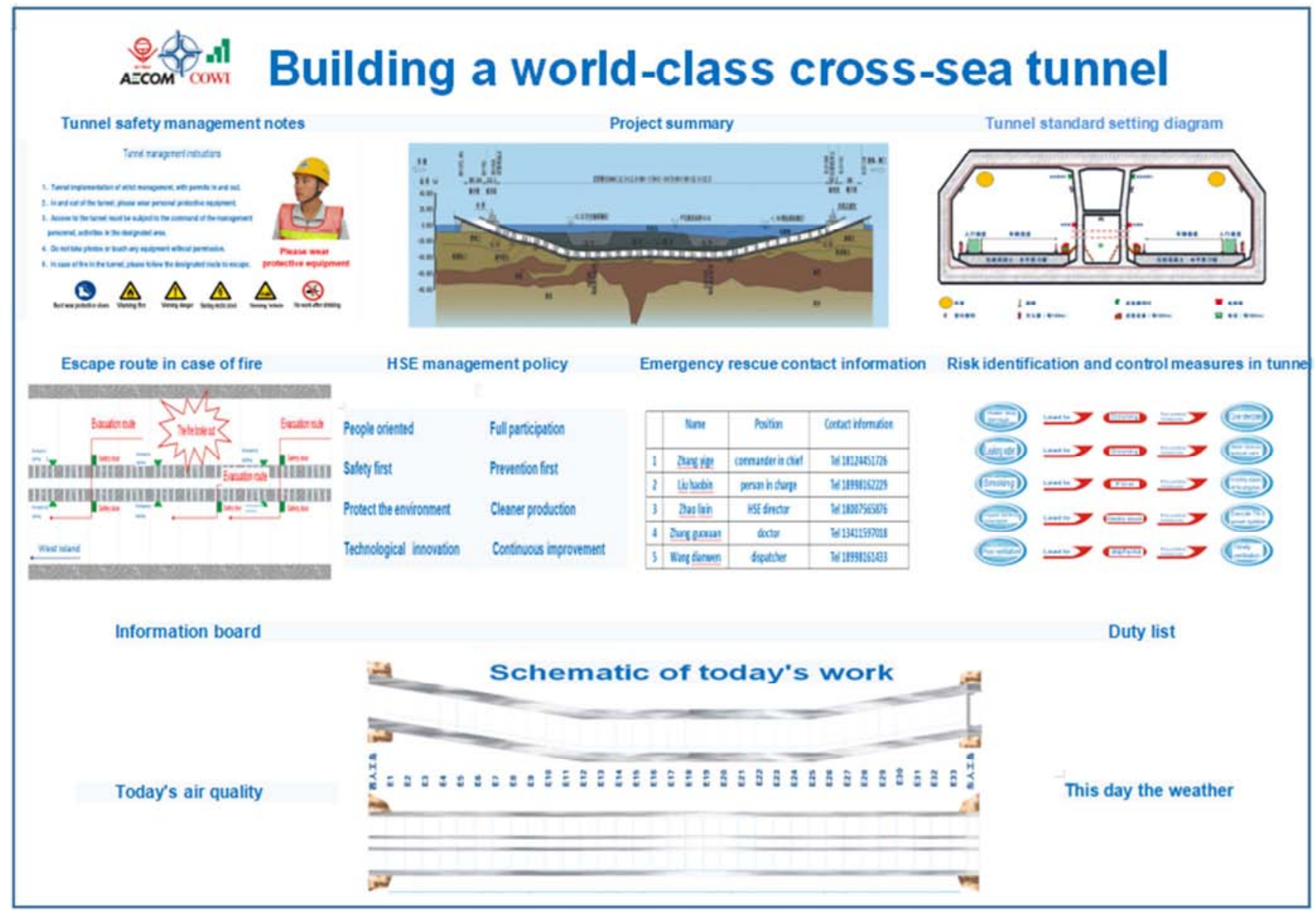

Figure 3. Construction sign.

\section{Video Monitoring and Communication in Immersed Tunnel}

An industrial-grade high-definition camera capable of $360^{\circ}$ rotation is installed at the entrance, exit and the important construction site of the tunnel. The 24-hour monitoring of the tunnel entry and exit personnel and the in-pipe operation is carried out, and the real-time picture in the tunnel is transmitted to the project general manager. The monitoring system can not only transmit image in real time, but also record automatically, and the whole construction process can be completely traced back [15]. As long as there is network, anyone can see the live construction situation at any place after logging in.

In order to facilitate communication within the tunnel, wired telephone is installed in the dispatch room and tunnel entrance, and each pipe joint of the tunnel is equipped with one wired telephone [16].

\section{Civilized Construction}

All construction shall apply for work area and work time in advance, and be surrounded by safety isolation measures. The materials in work area should be stowed neatly, and the waste should be sorted and cleaned out in time every day to ensure the site is clean and tidy [17].

With the continuous advance of the construction inside the immersed tunnel, the construction area continues to extend, and the task of on-site pavement cleaning is becoming more and more onerous. Manual cleaning will produce a certain amount of dust, which is not easy to discharge in the tunnel, causing harm to the health of operators. For this reason, the project department introduced a road sweeper. Road sweeper is a new type of high-efficiency cleaning equipment that integrates road sweeping, garbage collection and transportation. In addition to the chassis engine, the vehicle is equipped with a secondary engine. The four sweeping brushes are driven by hydraulic motor, with a variety of 
supporting equipment such as fans, dustbin, and water tanks. The vehicle can achieve ground cleaning, dust collection and watering the ground after cleaning at one time. [18].

With the tunnel construction continues to advance, the operating place is getting further and further. For this reason, the project department has set up environment-friendly portable toilets near the construction area and special personnel are arranged to clean them every day.

\section{The Conclusion}

In this paper, the main points of safety management of immersed tunnel of Hongkong-Zhuhai-Macao bridge are expounded from seven aspects according to the construction situation. Improving economic efficiency, ensuring safe production, and reducing accidents are the eternal pursuit of construction management. Therefore, when it comes to safety management, people oriented is the foremost principle. The operating environment can be improved by using scientific and technological means to promote safety management, strengthening safety control, and adhering to standardized management and civilized construction. Only in this way can the safety of both personnel and construction of the immersed tunnel be protected.

\section{References}

[1] Introduction of Hong Kong-Zhuhai-macao bridge. June 8, 2009.

[2] Tunnel construction, volume 37, phase 9, September, 2017.

[3] RFID tunnel construction personnel and equipment safety monitoring management system, December 10, 2014.

[4] Highway tunnel ventilation design rules. JTGT D702-02-2014.

[5] Liu ran. Comparison and application of automatic monitoring methods for PM 2.5 in ambient air [J]. Environment and development, 29 (5): 137-137, 2017.
[6] Ma Hongtao. Application and troubleshooting of air breathing apparatus in fire rescue sites [J]. Modern business industry, 2017 (24): 197-199.

[7] Construction site temporary electricity safety technical specification. JGJ46-2005.

[8] Hong Kong-Zhuhai-macao bridge island tunnel project immersed tunnel. Temporary power supply scheme az-ds i-927. August 16, 2015.

[9] Building design fire code. GB 5006-2014.

[10] Quan ding and Wang zhengjin. Safety analysis of hot work in projects under construction [J]. Enterprise technology development, 35 (16): 88-90, 2016.

[11] Code for safety management of hot work. QSY 1241-2009.

[12] Technical specifications for safety protection of water transport engineering construction. Jtj205-1-2008 [S]. People's communications press. 2008.

[13] Weng wenlin, Chen shaorun. Discussion on standardized management of highway tunnel construction [J]. China science and technology information, 2013 (13): 49-49.

[14] Engineering quality supervision bureau of the ministry of transport. Standardization guide for construction safety of highway and water transport projects [S]. Beijing: people's transportation press. 2013.

[15] Zhang weizong, He shuqiang, Li haipeng. Application of video monitoring system in the construction of long tunnel of expressway [J]. Transportation research, 2012 (6): 82-85.

[16] Zhu qingyun, Chen mei. Study on the scheme of wired emergency telephone system for railway tunnel [J]. Railway communication signal engineering technology, 201108 (6): 14-17.

[17] Wang, Yinggang. Safety and civilized construction management of construction projects [J]. China construction, 2016 (1): 190-190.

[18] Zhao, Chengming. Working principle and operation and maintenance of road sweeper [J]. Guide to getting rich through science and technology, 2013 (32): 118-118. 